\title{
A Bayesian Approach to Evaluating the Dynamics of Rice Production in Madagascar
}

\author{
Finaritra Solomampionona Maminirivo ${ }^{1,}$,, Koki Kyo $^{2}$ \\ ${ }^{1}$ Department of Agricultural Economics, Obihiro University of Agriculture and Veterinary Medicine, Obihiro-Hokkaido, Japan \\ ${ }^{2}$ Faculty of Management and Information Science, Niigata University of Management, Kamo-Niigata, Japan
}

Email address:

finaritrasm@gmail.com (F. S. Maminirivo)

${ }^{*}$ Corresponding author

\section{To cite this article:}

Finaritra Solomampionona Maminirivo, Koki Kyo. A Bayesian approach to evaluating the dynamics of rice production in Madagascar. International Journal of Agricultural Economics. Vol. 5, No. 2, 2020, pp. 43-48. doi: 10.11648/j.ijae.20200502.12

Received: February 25, 2020; Accepted: March 17, 2020; Published: April 28, 2020

\begin{abstract}
In Madagascar, domestic rice production does not meet the local demand. Thus, increasing productivity is crucial for ensuring food security for a booming population. The last two decades have been marked by technological improvements in support of a vision of agricultural development. The main objective of the present study is to evaluate rice productivity in Madagascar based on changes in technology and the planted area during the period from 1961 to 2017. To conduct our analysis, we construct a set of statistical models involving time-varying parameters that capture the changes in productivity and progress in rice production technology. To estimate these time-varying parameters, we apply Bayesian methods based on the smoothness prior approach. The estimates for variances in system noise show that the proposed model is well fitted to the data. In addition, the results provide the interesting finding that technological change is estimated to be elastic, with values increasing from 1 to 8 during the six decades of the study period. However, the planted area estimates are inelastic, despite positive values fluctuating around $0.9-1$. Thus, rice productivity in Madagascar is highly dependent on technology, although more time is required before a positive response is seen.
\end{abstract}

Keywords: Rice Productivity, Madagascar, Bayesian Statistical Modeling, State-space, Kalman Filter

\section{Introduction}

In Madagascar, the agricultural economy revolves around rice production, which is a staple food item accounting for $44 \%$ of local food consumption, as well as the most lucrative crop, accounting for $30 \%$ of total income [1]. However, the agricultural sector has performed poorly over the last few decades, with domestic production failing to satisfy local demand, necessitating the importation of rice [2]. This has been at least partly attributable to the booming population, which is mainly composed of rural farming families, and has increased from five million in 1960 to more than 25 million in 2019 [3, 4]. Thus, food security has become a crucial issue, and improving rice productivity is a major challenge [5]. Technological improvements have provided support for rice farmers via agricultural projects undertaken by international organizations in an effort to enhance productivity in a sustainable way $[6,7,8]$.

Thus, this study focuses on evaluating the dynamics of rice production in Madagascar. We consider the changes in technology related to rice production and production elasticity with respect to the planted area (hereafter planted area elasticity). The main purpose of this study is the estimation of the time-varying technological elasticity and the time-varying planted area elasticity in Madagascar during the period 1961-2017. Thus, we construct a set of Bayesian linear models with smoothness priors for the time-varying parameters. The models can be expressed in state-space form, and thus we can use Kalman filter algorithms to estimate the time-varying parameters that are involved in the state vector. We hypothesize that rice productivity can be explained by two main factors: improved technology over time, and decreasing planted area elasticity as the planted area has increased. This approach has been used in the few studies applying advanced statistical methods to analyze rice productivity in Madagascar, while other studies have used traditional econometric models.

The rest of the paper is structured as follows: Section 2 
explains the data used in the analysis and presents the model specifications and the Kalman filter methodology. Section 3 analyzes the estimated results and presents a discussion of the findings. Section 4 concludes.

\section{Materials and Methods}

\subsection{Data}

In this study, we estimated and analyzed rice productivity in Madagascar based on annual time-series data for planted area (ha) and crop yield (tons) during the period from 1961 to 2017. The data were obtained from the FAOSTAT database (2019). Figure 1 shows the analytical process.

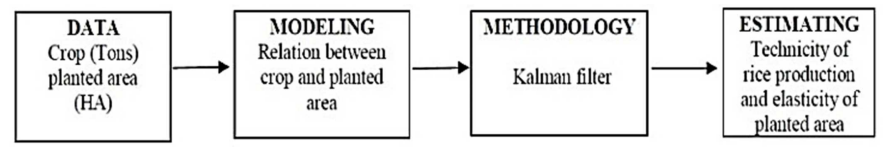

Figure 1. The analytical process.

Table 1. Descriptive statistics for rice planted area, yield, and production in Madagascar.

\begin{tabular}{llll}
\hline DESCRIPTIVE & PLANTED AREA & YIELD & PRODUCTION \\
\cline { 2 - 4 } STATISTICS & HA & KG/HA & TONS \\
\hline MEAN & $1,101,543$ & 2,3 & $2,543,013$ \\
MINIMUM & 730,000 & 1,66 & $1,465,000$ \\
MAXIMUM & $1,307,043$ & 4,4 & $4,737,965$ \\
\hline
\end{tabular}

Table 1 presents the descriptive statistics based on the raw data. The rice planted area in Madagascar accounts for $12 \%$ of the African total of 8 million hectares and $5 \%$ of the global total of 160 million hectares. Madagascar is one of the three biggest producers of rice in Africa, together with Egypt and Nigeria. The average yield in Madagascar is less than 0.7 tons/ha, while the average global yield is 3 tons/ha [9].

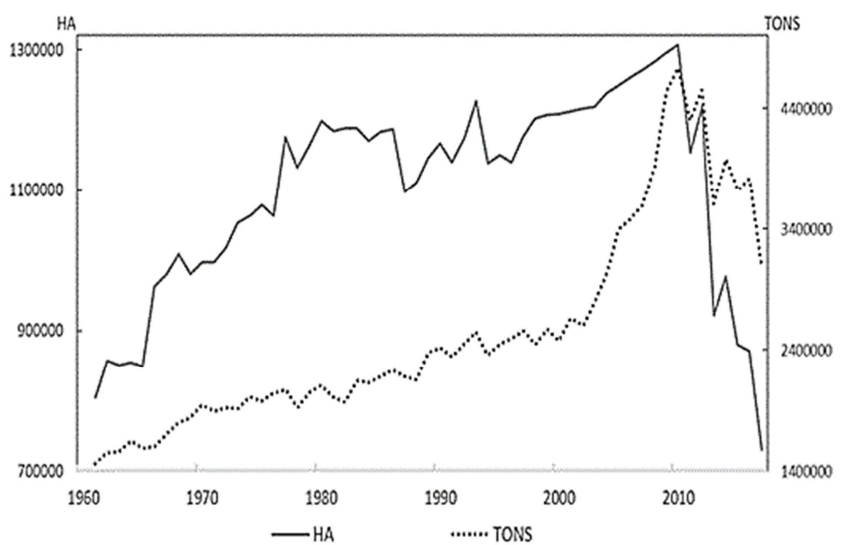

Figure 2. Planted area (solid area) and rice production (dotted line) in Madagascar from 1961 to 2017.

The Figure 2 shows the time-series data for the rice planted are and rice production in Madagascar from 1961 to 2017. There are similar trends in relation to the planted area and rice production over this period, whereby they both increased from 1960 to 2010, after which they both decreased. This reflects the major political crisis in 2009 that impacted $60 \%$ of the rice crop because foreign financial aid ceased until 2013 and interrupted international agricultural development projects, also the impact of climate change causing dryness in 2016 [10-13]. It can be seen that the planted area roughly doubled from 1960 to 2010, peaking at almost 1.3 million hectares before decreasing sharply to about half that by 2017 . Thus, in one decade, Madagascar lost almost half of the rice planted area that had been developed during the five preceding decades. In terms of production, between 1960 and 2000, annual production increased by $71 \%$ from 1.4 million tons to 2.4 million tons. Then, from 2000 to 2010 , production increased by $83 \%$ from 2.4 million tons to 4.4 million tons before declining sharply after 2010 .

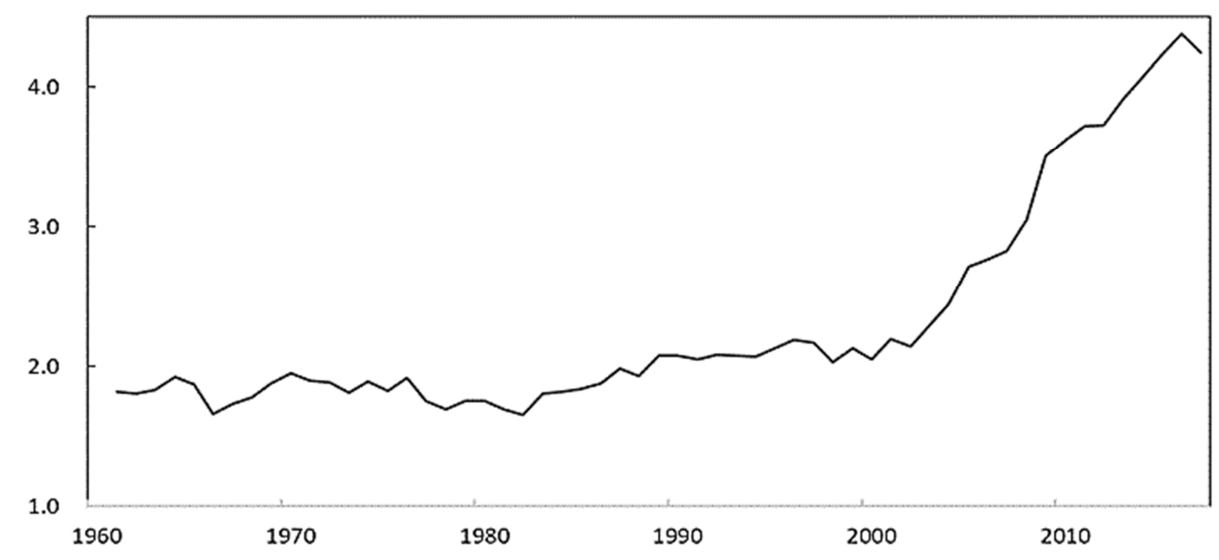

Figure 3. Rice crop yield from 1961 to 2017.

Using the time-series data for the planted area and rice production, we can calculate time-series data for crop yields during the same period (see Figure 3). It can be seen from Figure 3 that yields remained relatively constant at around 2 tons/ha during the period 1961-2000, after which they steadily increased to a peak of 4 tons/ha in 2017.

\subsection{Methodology}

\subsubsection{Model Specification}

The model for the production function was constructed using data from the period 1961-2017. We followed Jin and Jorgenson and Kyo et al., who constructed models in a form of 
a Cobb-Douglas production function based on the assumption of constant elasticity of substitution $[14,15]$. For the purpose of the present study, we constructed a production function as follows:

$$
Y_{n}=A_{n} z_{n}^{\gamma_{n}} E_{n} \text { with } 0<\gamma_{\mathrm{n}}<1,
$$

where $Y_{n}$ denotes rice production, $Z_{n}$ denotes the planted area, $A_{n}$ denotes the technology factor, $\gamma_{n}$ is the planted area elasticity, and $E_{n}$ is an error term. An important feature of the model shown in Eq. (1) is that the parameters $A_{n}$ and $\gamma_{n}$ are time-varying, allowing us to analyze the dynamic relationship between rice production $\left(Y_{n}\right)$ and the planted area $\left(Z_{n}\right)$.

Taking the logarithm of both sides of Eq. (1), the following relationship is obtained:

$$
\log Y_{n}=\log A_{n}+\gamma_{n} \log Z_{n}+\log E_{n} .
$$

This can be expressed as follows by setting $y_{n}=\log Y_{n}$, $a_{n}=\log A_{n}, z_{n}=\log Z_{n}$, and $e_{n}=\log E_{n}$ :

$$
\mathrm{y}_{\mathrm{n}}=\mathrm{a}_{\mathrm{n}}+\gamma_{\mathrm{n}} \mathrm{z}_{\mathrm{n}}+\mathrm{e}_{\mathrm{n}}, \quad \mathrm{e}_{\mathrm{n}} \sim \mathrm{N}\left(0, \sigma^{2}\right)
$$

To obtain stable estimates of the time-varying parameters an and $\gamma \mathrm{n}$, we use a Bayesian modeling method. We regard the time-varying parameters an and $\gamma \mathrm{n}$ as random variables and introduce a set of smoothness priors for them as follows (for more information about the smoothness priors [16],

$$
\begin{array}{ll}
\mathrm{a}_{\mathrm{n}}=2 \mathrm{a}_{\mathrm{n}-1}-\mathrm{a}_{\mathrm{n}-2}+\mathrm{v}_{\mathrm{n} 1}, & \mathrm{v}_{\mathrm{n} 1} \sim \mathrm{N}\left(0, \Psi_{1}^{2}\right), \\
\gamma_{\mathrm{n}}=2 \gamma_{\mathrm{n}-1}-\gamma_{\mathrm{n}-2}+\mathrm{v}_{\mathrm{n} 2}, & \mathrm{v}_{\mathrm{n} 2} \sim \mathrm{N}\left(0, \Psi_{2}^{2}\right) .
\end{array}
$$

The models in Equations (2) and (3) can be expressed in a matrix-vector form as follows:

$$
\begin{aligned}
& {\left[\begin{array}{c}
a_{n} \\
a_{n-1} \\
\gamma_{n} \\
\gamma_{n-1}
\end{array}\right]=\left[\begin{array}{cccc}
2 & -1 & 0 & 0 \\
1 & 0 & 0 & 0 \\
0 & 0 & 2 & -1 \\
0 & 0 & 1 & 0
\end{array}\right]\left[\begin{array}{l}
a_{n-1} \\
a_{n-2} \\
\gamma_{n-1} \\
\gamma_{n-2}
\end{array}\right]+\left[\begin{array}{ll}
1 & 0 \\
0 & 0 \\
0 & 1 \\
0 & 0
\end{array}\right]\left[\begin{array}{l}
V_{n 1} \\
V_{n 2}
\end{array}\right],} \\
& \mathrm{y}_{\mathrm{n}}=\left[\begin{array}{llll}
1 & 0 & \mathrm{z}_{\mathrm{n}} & 0
\end{array}\right]\left[\begin{array}{c}
a_{n} \\
a_{n-1} \\
\gamma_{n} \\
\gamma_{n-1}
\end{array}\right]+\mathrm{e}_{\mathrm{n}} .
\end{aligned}
$$

\subsubsection{The Kalman Filter}

The Kalman filter is a recursive algorithm that is used to find an optimal estimation of the state in a state-space model and to estimate time-varying random variables that cannot be observed based on a set of noisy measurements. There are two steps involved in the Kalman filter algorithm: prediction and filtering. In the prediction step, the Kalman filter provides the mean of the current state variables and the covariance of the predictive error. Filtering incorporates the new measurement at the corresponding time point into the prior information that is obtained in the prediction step to obtain an improved posterior distribution for the present state $[17,18,19]$. However, before using the Kalman filter, we need to construct a state-space model to enable a state to be estimated. Generally, a state-space model involves a state (or system) equation and a measurement (or observation) equation [20]. Consider the dynamic system as follows:

$$
\begin{gathered}
x_{n}=F_{n} x_{n-1}+G_{n} v_{n} \quad \text { (state equation), } \\
y_{n}=H_{n} x_{n}+w_{n} \quad \text { (measurement equation), }
\end{gathered}
$$

where, $x_{\mathrm{n}}$ is the state vector (object of estimation), $y_{\mathrm{n}}$ is the observable time series, $v_{n} \sim \mathrm{N}\left(0, Q_{n}\right)$ is the system noise, $w_{\mathrm{n}} \sim \mathrm{N}\left(0, R_{\mathrm{n}}\right)$ is the observation noise, and $F_{n}, G_{n}$, and $H_{n}$ are the coefficient matrices. The system expressed in Equations (7) and (8) is called the state-space model. It can be seen that the model in Equations (5) and (6) is equivalent to the statespace model in Equations (7) and (8) if we set $x_{\mathrm{n}}=\left[a_{n} a_{n-1} \gamma_{n}\right.$ $\left.\gamma_{n-1}\right]{ }^{\mathrm{T}}, \quad Q_{n}=\operatorname{diag} .\left(\Psi_{1}^{2}, \Psi_{2}^{2}\right), \quad$ and $R_{n}=\sigma^{2}$ and construct appropriate coefficient matrices $F_{n}, G_{n}$, and $H_{n}$.

One of the features of the state-space modeling approach is that information related to past processes is merged into the current state. This is usually called a Markovian property [21]. Figure 4 shows a block diagram of the state estimation process for a dynamic system that is expressed as a statespace model [22].

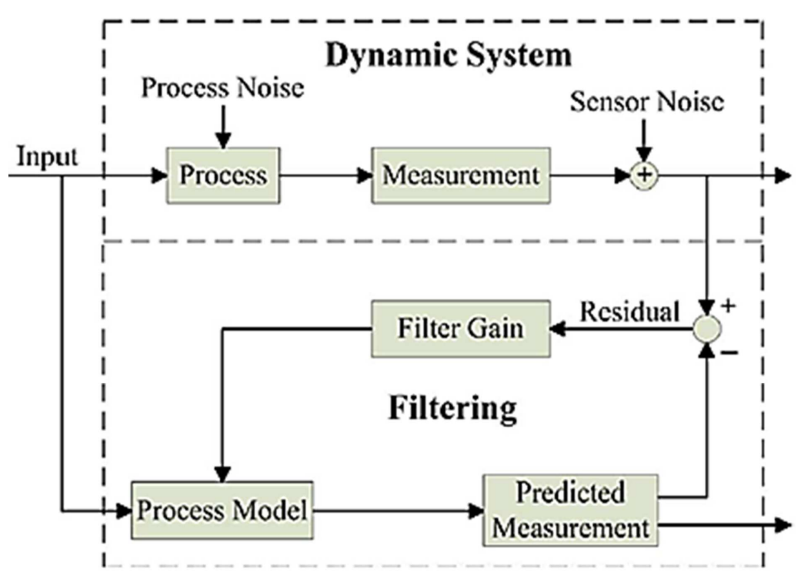

Figure 4. Block diagram of the state estimation process.

The Kalman filter algorithm is given by Equations (9)(13), where $x_{n \mid n-1}$ denotes the mean of the state vector at $n$ given observations up to time point $n$-1, e $V_{n \mid n-1}$ denotes the corresponding covariance matrix, and so on. For a set of observations $Y_{1: N}=\left\{y_{1}, y_{2}, \ldots, y_{N}\right\}$, we can obtain a set of estimates for the state by pursuing the Kalman filter for $n=1,2, \ldots, N-1, N$. Note that the Kalman filter starts from initial values of $x_{0 \mid 0}$ and $V_{0 \mid 0}$, which are provided in advance.

Prediction step:

$$
\begin{gathered}
x_{n \mid n-1}=F_{n} x_{n-1 \mid n-1} \\
\text { Vn|n-1=FnVn-1|n-1FnT }+ \text { GnQnGnT }
\end{gathered}
$$

Filtering step of the Kalman gain equation:

$$
\mathrm{K}_{\mathrm{n}}=\mathrm{V}_{\mathrm{n} \mid \mathrm{n}-1} \mathrm{H}_{\mathrm{n}}^{\mathrm{T}}\left(\mathrm{H}_{\mathrm{n}} \mathrm{V}_{\mathrm{n} \mid \mathrm{n}-1} \mathrm{H}_{\mathrm{n}}^{\mathrm{T}}+\mathrm{R}_{\mathrm{n}}\right)^{-1}
$$


Update step:

$$
\begin{array}{r}
x_{n \mid n}=x_{n \mid n-1}+K_{n}\left(y_{n}-H_{n} x_{n \mid n-1}\right) \\
V_{n \mid n}=\left(I-K_{n} H_{n}\right) V_{n \mid n-1}
\end{array}
$$

Another aspect of inference based on the state-space model is the smoothing step. Based on data $Y_{1: \mathrm{N}}=\left\{y_{1}, y_{2}, \ldots\right.$, $\left.y_{n}\right\}$ collected over a fixed time period $\{1,2, \ldots, N\}$, smoothing attempts to find the posterior distribution of the state $x_{n}$ conditional on $Y_{1: N}$ for any $n \in\{1,2, \ldots, N\}$. For linear Gaussian state-space models, this can be done precisely using the Kalman smoother, which consists of a Kalman filter plus subsequent recursive "backward smoothing" for $n$ $=(N, N-1, \ldots, 1)$ [23]. This is also called fixed-interval smoothing. The formula for fixed-interval smoothing is as follows [17]:

$$
\begin{gathered}
A_{n}=V_{n \mid n} F_{n}^{\mathrm{T}} V^{1}{ }_{n+1 \mid n} \\
x_{n \mid N}=x_{n \mid n}+A_{n}\left(x_{n+1 \mid N}-x_{n+1 \mid n}\right) \\
V_{n \mid N}=V_{n \mid n}+A_{n}\left(V_{n+1 \mid N^{-}} V_{n+1 \mid N}\right) A^{\mathrm{T}}{ }_{n} .
\end{gathered}
$$

However, when some elements in the matrices $F_{n}, G_{n}, H_{n}$, $Q_{n}$, and $R_{\mathrm{n}}$ are unknown parameters, it is necessary to estimate them in advance. Let $\theta$ denote the vector of the unknown parameters. In the model in Equations (5) and (6), $\theta$ contains the parameters $\sigma^{2}, \Psi_{1}^{2}$, and $\Psi_{2}^{2}$. Based on the Kalman filter predictive distribution of the time series, $y_{n}$ can be obtained with $y_{n \mid n-1}$ and $U_{n \mid n-1}$ denoting the mean and the covariance matrix, respectively. At time $n$, these can be calculated based on the results of the Kalman filter as follows:

$$
\begin{gathered}
\mathrm{y}_{\mathrm{n} \mid \mathrm{n}-1}=\mathrm{H}_{\mathrm{n}} \mathrm{x}_{\mathrm{n} \mid-1} \\
\mathrm{U}_{\mathrm{n} \mid \mathrm{n}-1}=\mathrm{H}_{\mathrm{n}} \mathrm{V}_{\mathrm{n} \mid \mathrm{n}-1} H_{n}^{\mathrm{T}}+\mathrm{R}_{\mathrm{n}} .
\end{gathered}
$$

From the Kalman filter algorithm, we can see that the results of the Kalman filter depend on the parameters $\theta$, hence $y_{n \mid n-1}$ and $U_{n \mid n-1}$ also depend on $\theta$. Thus, for given values of $\theta$, the density of the predictive distribution for $\mathrm{y}_{\mathrm{n}}$ is given by

$$
f_{n}\left(Y_{n} / Y_{1:(n-1)}, \theta\right)=\frac{1}{\sqrt{2 \pi U_{n \mid n-1}}} \exp \left\{-\frac{\left(y_{n}-y_{n \mid n-1}\right)^{2}}{2 U_{n \mid n-1}}\right\} .
$$

Based on this density, the likelihood function of $\theta$ can be defined by

$$
\mathrm{L}(\theta)=\mathrm{f}\left(\mathrm{Y}_{1: \mathrm{N}} \mid \theta\right)=\Pi_{n-1}^{N} \mathrm{f}_{\mathrm{n}}\left(\mathrm{y}_{\mathrm{n}} \mid \mathrm{Y}_{1:(\mathrm{n}-1)}, \theta\right),
$$

where the time-series data $Y_{1:(n-1)}=\left\{y_{1}, y_{2}, \ldots, y_{n-1}\right\}$, and so on. This likelihood function will generally be a complex nonlinear function of the parameters $\theta$, and thus the estimates for the parameters $\theta$ can be obtained by maximizing the likelihood function in Eq. (14) numerically with respect to $\theta$ $[23,24]$.

\section{Results}

Table 2. Estimates of the parameters.

\begin{tabular}{ll}
\hline Method: State space with Kalman filter & \\
Sample period & $1961-2017$ \\
Included and valid observations & 57 \\
$\Psi_{1}{ }^{2}$ & $3.35 * 10^{-4}$ \\
$\Psi_{2}{ }^{2}$ & $9.12 * 10^{-4}$ \\
$\sigma^{2}$ & $1.14 * 10^{-3}$ \\
Log likelihood (goodness of fit) & 30.86 \\
\hline
\end{tabular}

The panel in Table 2 shows the results of the estimation of the state-space model using the Kalman filter algorithm. In particular, $\Psi_{1}^{2}$ and $\Psi_{2}^{2}$ are the estimates for variances in the system noise, and $\sigma^{2}$ represents the variance in the observation noise.
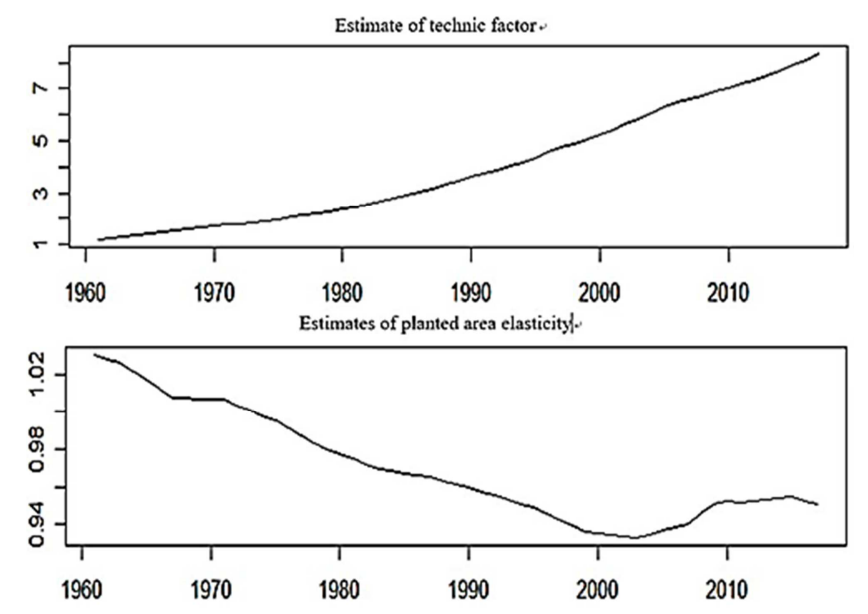

Figure 5. Estimates of the technology factor and planted area elasticity.

The upper panel in Figure 5 shows the estimates (mean) for the technology factor $\left(A_{n}=\exp \left(a_{n}\right)\right)$ and the lower panel shows the estimates for planted area elasticity $\left(\gamma_{n}\right)$. There is a continuous upward trend in the technology factor during the period, and it is eight times higher in 2017 than it was in 1961. This change in the technology factor has had a significant influence on productivity and yield in recent years. Conversely, planted area elasticity shows a significant downward trend, with values falling from around 1.04 in 1961 to around 0.92 in the early 2000s, reflecting the increase in the planted area. Since then, there has been a slight increase, with values rising to around 0.96 in 2017, which is not significant compared with the values seen in previous decades, and is related to the decrease in the planted area. Productivity has not responded sensitively to changes in the planted area, and there is a crossover between both elasticities where the level of technology has increased and the planted area has decreased. Thus, improvements in agricultural technology have not been accompanied by agricultural expansion. Technological change has had a greater effect than the planted area on productivity.

Technological change elasticity is a time-varying indicator that changes positively over time. It is influenced by agricultural policies that contribute to diversifying and enhancing agricultural productivity [26, 27]. Madagascar's 
agricultural policy is marked by national agricultural projects and reforms via technological support and fertilizer distribution to rice farmers during the post-independence period from the 1960 s to the 1990 s, followed by a global policy of economic liberalization [28, 29, 30]. In addition, there has been increased investment in technology diffusion in relation to agricultural development projects, mainly by international organizations, since the early 2000 s $[1,30,31]$. The system of rice intensification technology was developed locally in the early 1990 s, but was not widely adopted. It has since been readapted in the context of agroecology, or smart agriculture for an improved rice intensification system [32, $33,34]$. A combination of these socio-agroeconomic policies has resulted in a gradual transformation in Madagascar's agricultural sector, although it will take time to fully evolve.

Meanwhile, the rice planted area is influenced by a lack of investment in irrigation infrastructure, vulnerability to climate change and extreme weather events such as cyclones, drought and lack of security in terms of land tenure [30, 35, 36]. In addition, the system of land transfers between generations through inheritance has become inefficient, as the average area of land per farmer has decreased from 1.2 hectares in 1985 to 0.25 hectares in 2016 as the rural population has increased [37, 38].

\section{Conclusion}

In the context of a population explosion and a vision of economic development, increasing agricultural productivity is a challenge that Madagascar must meet if it is to ensure food security. The demand for rice is likely to increase in the future, and thus evaluating the current state of rice productivity is crucial to implementing improved agricultural policies and practices.

In this study, we estimated the technology factor and planted area elasticities based on data for rice production and the rice planted area in Madagascar during the period from 1961 to 2017 using a state-space modeling approach. Using recursive prediction and updating, we obtained estimates for the technology factor and planted area elasticities using a set of optimal algorithms with minimum error and time-varying indicators.

The estimates for variances in system noise showed that the proposed model is well-fitted to the data. There is a significant upward trend in technology factor elasticity, with values rising from 1 to 8 during the study period, while, while the planted area elasticity values fluctuate between 0 and 1, decreasing during the period from 1961 to 2000 before increasing slightly from 2007 to 2017 . These results show that technological change has had a greater effect on productivity than rice planted area. In addition, our hypotheses are supported. Importantly, these findings are helpful for decision-makers aiming to develop strategies to support ongoing technological improvement and also increase the rice planted area to enhance rice productivity in Madagascar.

\section{Acknowledgements}

This work is partially supported by a Grant-in-Aid for Scientific Research (C) (19K01583) from the Japan Society for the Promotion of Science. Also, partially supported by JICA through African Business Education Initiative. We thank Geoff Whyte, MBA, from Edanz Group (www.edanzediting.com/ac) for editing a draft of this manuscript.

\section{References}

[1] Chauvin N. D., Porto G., and Mulangu F., 2017. Agricultural Supply Chains, Growth and Poverty in Sub-Saharan Africa: Market Structure, Farm Constraints and Grass-root Institutions. Chapter 8: The case of Madagascar. Springer, Advances in African Economic, Social and Political Development. 195p, p 143-149. Doi: 10.1007/978-3-662-53858-6

[2] Maret F., 2007. Distortions to Agricultural Incentives in Madagascar. George Washington University, Agricultural Distortions Working Paper 53. 50p.

[3] MAEP (Ministère de l'Agriculture, de l'Elevage et de la Pêche à Madagascar), 2019. Système de production des statistiques sur les coûts de production agricole à Madagascar test sur le riz, le manioc, le café et la vanille. Global Strategy improving Agricultural and Rural Statistics, African Development Bank, European Union. 124p.

[4] INSTAT (Institut National de Statistique Madagascar), 2019. Troisième Recensement General de la Population et de l'habitation (RGPH-3).

[5] Hume D. W., 2009. Vary Gasy: Folk Models of Rice and Implications for Agricultural Development in Eastern Madagascar. Etudes Ocean Indien. Open Editions Journal 42-43. 12p. Doi: 10.4000/oceanindien.812

[6] Balasubramanian V., Sie M., Hijmans R. J. and Otsuka K., 2007. Increasing rice production in Sub-Saharan Africa: Challenges and Opportunities. Elsevier, Advances in Agronomy 94, p 55-133. Doi: 10.1016/S0065-2113(06)94002-4

[7] Saito K., Dieng I., Toure A. A., Somado E. A. and Wopereis M. C. S., 2015. Rice yield growth analysis for 24 African countries over 1960-2012. Elsevier, Global food security 5: p 62-69. Doi: 10.1016/j.gfs.2014.10.006

[8] Varma P., 2017. Rice productivity and food security in India: A study of the Rice system Intensification. Springer. Centre for Management in Agriculture (CMA), $\mathrm{N}^{\circ} 250$. Indian Institute of Management Ahmedabad (IIMA). Doi: 10.1007/978-981-10-3692-7

[9] Bhagirath S. C., Khawar J., and Gulshan M., 2017. Rice Production Worldwide. Springer International Publishing. 561p. Doi: 10.1007/978-3-319-47516-5.

[10] Ploch L. and Cook N., 2012. Madagascar's political crisis: the impact of the political crisis on the economy. Congressional Research Service Report. P 14-16.

[11] The World Bank, 2013. Madagascar: Measuring the Impact of the Political Crisis. https://www.worldbank.org/en/news/feature/2013/06/05/mada gascar-measuring-the-impact-of-the-political-crisis. 
[12] Razafindrakoto M., Roubaud F., and Wachsberger J. M., 2018. The puzzle of Madagascar's economic collapse through the lens of social sciences. La lettre d'information de DIAL, Developpement Institution et Mondialisation. 12p.

[13] FEWSNET, 2018. Madagascar food security outlook, Poor harvests will result in a harder lean season in Southeastern Madagascar. USAID. 13p.

[14] Jin H. and Jorgenson, 2010. Econometric modeling of technical change. Elsevier, Journal of Econometrics. P 205-209. Doi: 10.1016/j.jeconom.2009.12.002

[15] Kyo K., Noda H., and Kitagawa G., 2013. Bayesian analysis of unemployment dynamics in Japan. Asian Journal of Management Science and Applications, Vol. 1, No. 1. P 4-25. Doi: 10.1504/AJMSA.2013.056005

[16] Kitagawa G. and Gersh W., 1996. Smoothness Priors Analysis of Time Series. Springer, New York.

[17] Kitagawa G., 2010. Introduction to time series modeling. CRC Press, New York

[18] Inglesi-Lotz R., 2011. The evolution of price elasticity of electricity demand in South Africa: A Kalman filter application. Elsevier, Energy Policy. Doi: 10.1016/j.enpol.2011.03.078

[19] Tesfahun Berhane, Nurilign Shibabaw, Aemiro Shibabaw, Molagin Adam, and Abera A. Muhamed, 2018. Forecasting the Ethiopian Coffee Price Using Kalman Filtering Algorithm. Journal of ressources ecology, 9 (3): 302-305. Doi: $10.5814 /$ j.issn.1674-764x.2018.03.010

[20] Chansu L., 2019. Estimating residential and industrial city gas demand function in the Republic of Korea - A Kalman Filter application. MDPI, Sustainability. 12p. Doi: 10.3390/su11051363.

[21] Fernando V. G., Tomas M. M., and Juan M. L., 2015. Dynamical approach for real-time monitoring of Agricultural Crops. IEE Geosience and Remote sensing. Doi: 10.1109/TGRS.2014237.

[22] Afsharia, Gadsdenb, and Habibia, 2017. Gaussian filters for parameter and state estimation: A general review of theory and recent trends. Elsevier Signal Processing 135, p 218-238. doi: 10.1016/j.sigpro.2017.01.001.

[23] Katzfuss M., Stroudb J. R., and Wikle C. K., 2016. Understanding the Ensemble Kalman Filter. The American Statistician. Taylor and Francis Group. Volume 70, p 350-357.

[24] Kalman R. E., 1960. A New Approach to Linear Filtering and Prediction Problems. Transactions of the ASME-Journal of Basic Engineering, 82 (Series D), p 35-45.

[25] Kyo K., and Noda H., 2016. Correspondence between Turning Points in Trend of Oil Price and Business Cycles in Japan, Proceedings of 2nd International Conference on Sustainable Development. Atlantis Press, Advances in Engineering Research, volume 94. P 388-396.

[26] Hoeffler H., 2011. The Political Economy of Agricultural Policies in Africa: History, Analytical Concepts and Implications for Development Cooperation. Quarterly Journal of International Agriculture 50. P 29-53.
[27] Ssozi J., Asongu S. A., and Amavilah V., 2018. The Effectiveness of Development Aid for Agriculture in Sub-Saharan Africa. African Governance and Development Institute. Munich Personal RePEc Archive Paper No. 88530. P 48 .

[28] Barrett, 1994. Understanding Uneven Agricultural Liberalisation in Madagascar. Cambridge University Press, the journal of modern African studies $\mathrm{n}^{\circ} 32, \mathrm{p}$ 449-476.

[29] Randrianarisoa J. C., and Minten B., 2001. Agricultural Production, Agricultural Land and Rural Poverty in Madagascar. Ilo Program, Cornell University. 46p.

[30] Penot E., Dabat M. H., Rakotoarimanana A., and Grandjean P., 2014. L'évolution des pratiques agricoles au lac Alaotra à Madagascar. Une approche par les temporalités. Biotechnology Agronomy Social Environnemental Journal. V8 (3), p 329-338.

[31] Liu P., Koroma S., Arias P., and Hallam D., 2013. Trends and impacts of foreign investment in developing country agriculture: evidence from case studies. Food and Agriculture Organization of the United Nations. 382p.

[32] Moser C., and Barrett, 2006. The complex dynamics of smallholder technology adoption: the case of SRI in Madagascar. IAAE, Agricultural Economics n³5, p 373-388. Doi: $10.1111 / \mathrm{j} .1574-0862.2006 .00169 . \mathrm{x}$

[33] Dabat M., Jenn-Treyer O., Grandjean P., Vallois P., Du Portal D., and Chalvin A.; 2008. Innovation technique et réduction de la pauvreté à Madagascar: débat revisité sur la pertinence du système de riziculture intensive. MAEP Madagascar, Agence Française pour le Développement. Document de travail BV lac $\mathrm{n}^{\circ} 6.29 \mathrm{p}$.

[34] Serpentie G., 2017. Le système de riziculture intensive ou « SRI » à Madagascar. Entre légende urbaine et innovation rurale. Anthropologie et Développement. Open Editions Journal $\mathrm{n}^{\circ} 16-17$, p 67-99. Doi: 10.4000/anthropodev.588

[35] Minten B. and Barrett C., 2008. Agricultural Technology, Productivity, and Poverty in Madagascar. Elsevier, World Development Vol. 36, No. 5, p. 797-822. Doi: 10.1016/j.worlddev.2007.05.004

[36] Harvey C. A., Rakotobe Z. L., Rao N. S., Dave R., Razafimahatratra H., Rabarijohn R. H., Rajaofara H., and MacKinnon J. L., 2014. Extreme vulnerability of smallholder farmers to agricultural risks and climate change in Madagascar. Philosophical Transactions of the Royal Society. B369: 20130089. 12p. Doi: 10.1098/rstb.2013.0089

[37] Minten B., Dorosh P., Dabat M. H., Jenn-Treyer O., and Magnay J., Razafintsalama Z., 2006. Rice markets in Madagascar in disarray: Policy options for increased efficiency and price stabilization. Washington, World Bank. Africa Region Working Paper Series No. 101, cirad-00773025f. $77 \mathrm{p}$.

[38] FAO, 2016. More effective and sustainable investments in water for poverty reduction. Water for the rural poor, Agricultural Water Management Investment Project. http://www.fao.org/in-action/water-for-poverty-in-africa/coun tries/madagascar 